\title{
An overview of the use of Facebook in National Weather Services
}

\author{
Virginia Palacio $^{1,2}$, Olatz Principe ${ }^{1,2}$, Maialen Martija ${ }^{1,2}$, and Santiago Gaztelumendi ${ }^{1,2}$ \\ ${ }^{1}$ Basque Meteorology Agency (Euskalmet), Parque tecnológico de Álava, Avda. Einstein 44 Ed. 6 Of. 303, \\ 01510 Miñano, Álava, Spain \\ ${ }^{2}$ TECNALIA, Meteorology Area, Parque tecnológico de Álava, Avda. Albert Einstein 28, \\ 01510 Miñano, Álava, Spain
}

Correspondence to: Santiago Gaztelumendi (santiago.gaztelumendi@tecnalia.com) and Virginia Palacio (virginia.palacio@tecnalia.com)

Received: 14 January 2016 - Revised: 31 August 2016 - Accepted: 31 August 2016 - Published: 13 October 2016

\begin{abstract}
National Meteorological Services (NMSs) use different "classical" tools in order to diffuse meteorological information, including television, radio, newspaper, phone, e-mail and websites. In recent years, new communication technologies and, in particular, the rapid expansion of Facebook allows users to efficiently exchange information and to easily share it with a large part of the population.

Facebook is one of the most used social networks and it represents a perfect virtual platform to share information and to promote active and immediate interaction amongst users. This is why many NMSs develop new communication strategies and incorporate this tool for different purposes. Some NMSs not only provide forecast, real-time observed data and other routine information, but they also upload videos (for example, with the weatherperson explaining the forecast or short reports) and amazing pictures taken by followers. In addition, they also give educational and didactic information (above all about climatic issues) and organize photographic competitions.

In this paper, firstly, we investigate when Facebook was introduced in different NMSs worldwide as an additional tool for the diffusion of meteorological information. Then, we propose a classification of these NMSs based on the success of their Facebook page, i.e. on the number of followers. Finally, we select some representative cases of NMSs and we analyze how Facebook is used to improve their services.
\end{abstract}

\section{Introduction}

Facebook is a social network and it was originally born as a website for students from Harvard University in 2004. A month after its creation, Facebook became a virtual platform to allow new students to connect to the campus. More than half of students from Harvard were registered in the platform during the first month of its creation. Facebook begins to be used by students from other universities a month later and by the end of that year, it already had one million students. In 2005, a version for companies was launched and, it has been opened to anyone older than 13 years (with a valid e-mail) since 2006, despite protests made by many users, since it would lose the student base for which it is born. Between 2007 and 2008, it was translated into other languages (starting with the Spanish language and later with French and German) in order to promote its expansion out of the US. In 2009, Facebook finished the year with 350 million users, reaching 800 million in 2011 (Facebook, 2016).

Facebook has around 1.350 million active users per month (on October 2014) and, occasionally, more than $80 \%$ use the mobile to connect to their accounts. This number reaches 399 million monthly users, taking into account people who access Facebook using only a mobile device (phone or tablet), without ever turning on a computer.

The way NMSs (National Meteorological Services) communicate with the public changes with the emergence of social networks, especially with Facebook and Twitter. A new form of communication is established not only for PC users, 


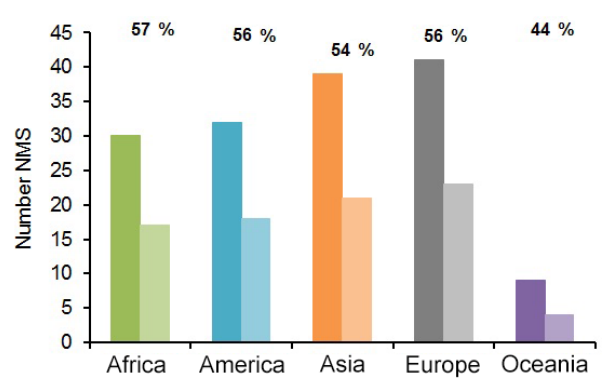

Figure 1. Percentages of NMSs which have accounts on Facebook by continents (May 2015). Dark color refers to total NMSs and light one to NMSs with Facebook account.

but also for the ones who use mobile phones or tablets. The use of these social networks, as tools of communication, has evolved since it appears. Nevertheless, NMSs develop new communication strategies and incorporate Facebook for different purposes, since the use of social networks changes from one meteorological services to another (WMO, 2001, 2007; Gill and Kreft, 2012). These new technologies make the diffusion of meteorological information to be almost instantaneous, close and highly useful for the general population. So nowadays, we could consider them almost indispensable (Palacio et al., 2014; Gaztelumendi et al., 2013, 2015).

\section{Meteorological services and Facebook}

In recent years, new technologies have become one of the most important sources of information transmission in NMSs. Social networks increase their number of users quickly. Amongst them, Facebook stands out with the greatest number of users in the world (Karakayali and Kilic, 2013). NMSs join this virtual network, and around $50 \%$ of weather services have an active account on Facebook (Europe almost $60 \%$, Oceania $44 \%$; see Fig. 1).

The first weather service joining Facebook was the Irish Meteorological Service, in the middle of 2009 (29 July 2009). Since then and until 2012, increasingly NMSs have joined Facebook. Thereafter, though there are new incorporations every year, this number falls. We have to take into account that the number shown in Fig. 2 corresponds only to the first five months of 2015 .

When you like a page on Facebook, you only have to click "Like", which means that you start to follow that page. Therefore, you become follower and can see all their posts, updates and news. Facebook accounts of NMSs with a huge number of Likes (followers) are fairly spread worldwide. Thus, if we consider all the NMSs accounts all over the world, the Philippine Atmospheric Geophysical and Astronomical Services Administration (Pagasa) account stands out above the rest of them, with more than a million Likes. The Bureau of Meteorology of Australia and US National Weather Service (NWS) are respectively in second and third

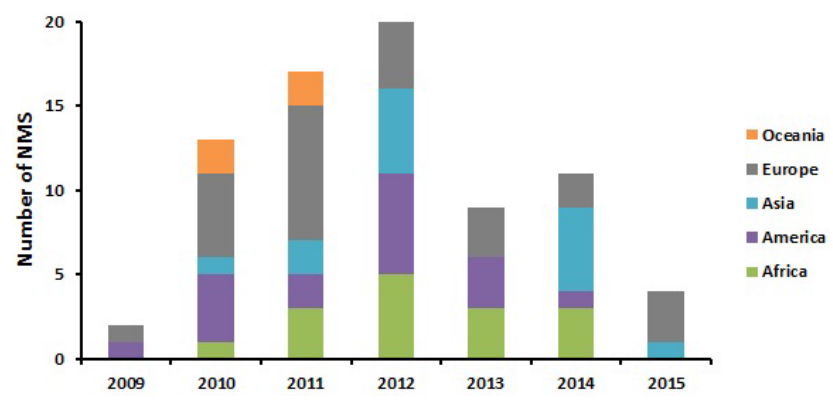

Figure 2. Yearly distribution of NMSs incorporation on Facebook (May 2015).

place. We have to descend until the 26th position to find the first African account, which is Department of Meteorological Services of the Republic of Botswana, with nearly ten thousand Likes (Fig. 3, data are from May 2015 and this information continuously changes).

Now we analyze the Likes which NMSs accounts receive according to their potential followers, i.e. the number of inhabitants from each country. Despite the fact that Pagasa remains the most noticeable one in Asia, it descends to sixth place. The Australian account is in fifth place and NWS falls to in the 32 nd position. In this case, a European account stands out above the others, the Malta Airport MetOffice account with almost 50000 Likes per million population (Fig. 4). We have to take into account that this NMS is included in the Airport Service but, as it has so many Likes, we think it could be notable.

\section{Analysis of usage}

The type of information provided by the different NMSs and the use they do on their Facebook pages varies from one to another. Accordingly, we select some weather services worldwide in order to analyze all this variety of contents (see Gaztelumendi et al. (2015) for similar analysis focusing on Twitter).

In Europe, we consider MetOffice (http://www.facebook. com/metoffice, in UK), Deutscher Wetterdienst (DWD, http://www.facebook.com/DeutscherWetterdienst, in Germany), Met Éireann (http://www.facebook.com/ Met-Éireann-123518233000, in Ireland) and Aemet (http://www.facebook.com/AgenciaEstatalMeteorologia, in Spain), besides the regional services Meteogalicia (http://www.facebook.com/meteogalicia.es, in Galicia) and Meteocat (http://www.facebook.com/meteocat, in Catalonia). In the American continent and in Oceania, we assess the National Weather Service (NWS, $\mathrm{http} / / / \mathrm{www}$. facebook.com/NWS, in USA) and the Bureau of Meteorology (http://www.facebook.com/ bureauofmeteorology, in Australia). And finally, in Asia, we select the Philippine Atmospheric, Geophysi- 


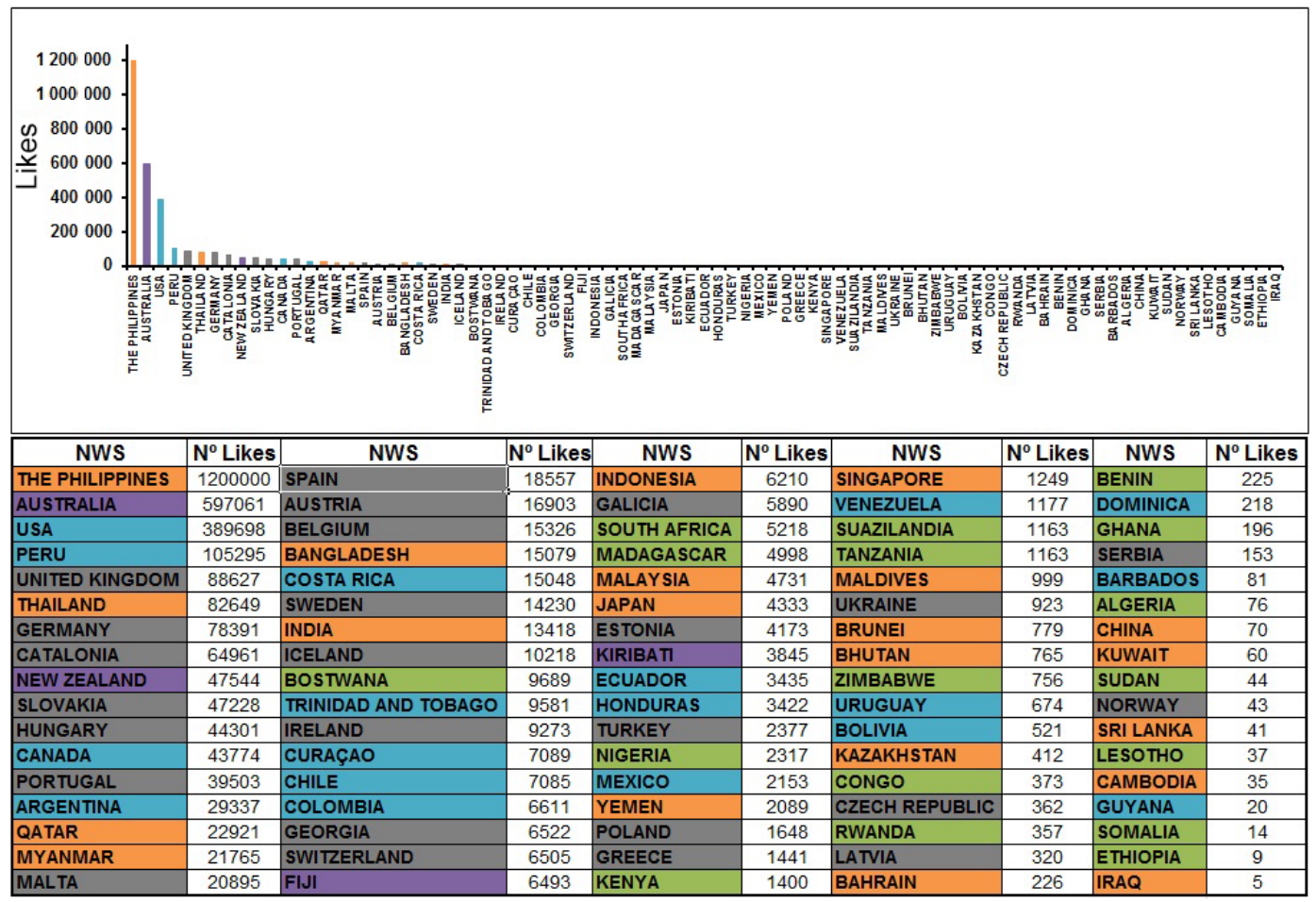

Figure 3. Number of Likes of NMSs' Facebook accounts (May 2015).

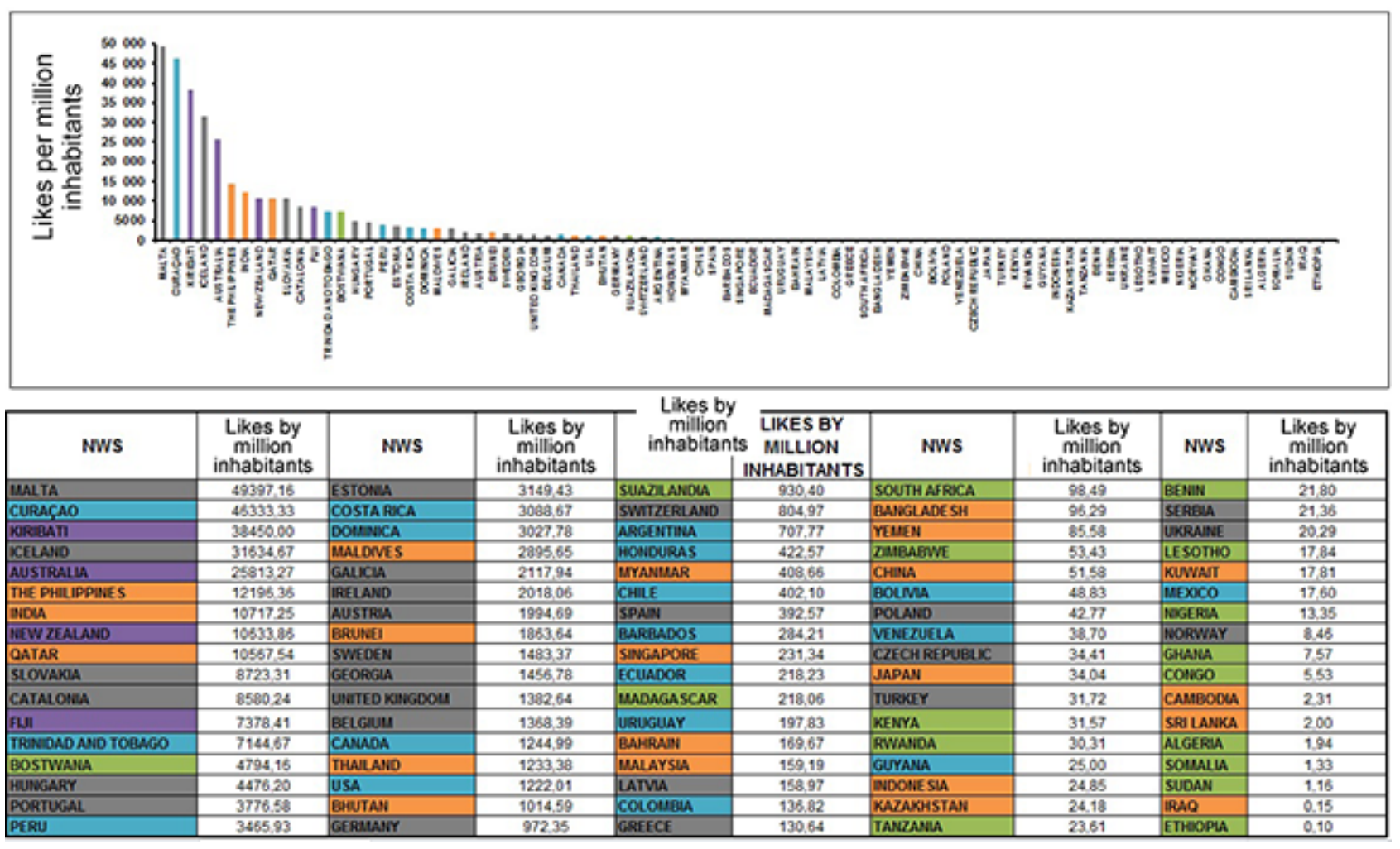

Figure 4. Likes by million inhabitants of NMSs' Facebook accounts (May 2015). 


\begin{tabular}{|c|c|c|c|c|c|c|c|c|c|}
\hline & Eat & (ब) & MEMeT & (9) & $\begin{array}{l}\text { metcoo } \\
\text { cat }\end{array}$ & P. & 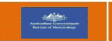 & 5 & $T+3$ \\
\hline Meteo service & MetOffice & DWD & AEMET & MetEireann & MeteoCat & MeteoGalicia & $\begin{array}{l}\text { Bureau of } \\
\text { Meteorology }\end{array}$ & NWS & Pagasa \\
\hline Country & U.K. & Germany & Spain & Irland & Catalunya & Galizia & Australia & USA & Philippines \\
\hline Starting date & $07 / 01 / 2010$ & $05 / 04 / 2011$ & $21 / 02 / 2013$ & $29 / 07 / 2009$ & $23 / 03 / 2011$ & $25 / 07 / 2011$ & $28 / 06 / 2011$ & $08 / 12 / 2009$ & $03 / 12 / 2012$ \\
\hline Number of likes & 89325 & 79649 & 18657 & 9285 & 65720 & 5890 & 597061 & 399370 & 1220586 \\
\hline PTAT & 6079 & 4169 & 327 & 159 & 1416 & 61 & 20241 & 10784 & 15741 \\
\hline Like rank $(0-100)$ & 89 & 73 & 52 & 38 & 47 & 36 & 79 & 67 & 65 \\
\hline $\begin{array}{l}\text { Posts daily } \\
\text { frequency }\end{array}$ & $0-3$ & $0-3$ & $0-4$ & $0-5$ & $0-10$ & $0-3$ & $0-3$ & $0-12$ & $0-50$ \\
\hline
\end{tabular}

Figure 5. General Facebook information about selected NMSs (May 2015).

cal and Astronomical Services Administration (Pagasa, http://www.facebook.com/PAGASA.DOST.GOV.PH, in Philippines).

In order to make this NMSs selection, we consider different aspects. On the one hand, we chose NMSs from different continents (America, Asia, Oceania and Europe). On the other hand, we consider diverse variables, such as the high number of followers (Pagasa, Australia and NWS), interaction with users (MetOffice and DWD), regional services (Meteocat and MeteoGalicia) or others with lower number of followers (Aemet and Met Éireann).

Regarding the weather services analyzed in Europe, the information provided through their respective Facebook pages changes a lot depending on the NMS (Gill and Kreft, 2012). Normally, though not daily, most of them provide some kind of forecast for festivals/holiday or special events (for example, Halloween, solar eclipse, sport events, etc.) or the trend for weekend or several days, usually accompanied by a link to the NMS website, with symbol maps or fronts. More sporadically, such as DWD, they do a preliminary projection of the tropical storms season or hurricanes. We have to highlight the videos provided by Aemet, Meteocat or DWD, where the weatherperson explains the forecast with symbol maps, fronts, satellite images, etc. And we also have to mention the personalized forecasts which meteorologists of MetOffice make, demanded by followers for specific regions and particular days. They have a great interaction with their users, either answering and commenting questions or giving thanks for pictures sent by followers.

In addition to directly accessing their Facebook pages, where we obtain the kind of information provided by them, we use Likealyzer (LikeAlyzer, 2016), a tool which allows you to examine and extract some information about these pages. Thus, we can obtain the number of people who create a story from a publication (PTAT, People Talking About That) or the LikeRank (a parameter between 1 and 100 and whose value represents how likeable a brand/page is, based on different indicators). So we can have an idea about users' interest in an account.

It is not surprising, therefore, the high value MetOffice achieves in the LikeRank rate, 89 of 100 (Fig. 5). Besides, more or less in a usual way depending on the weather services, they provide monthly or seasonal climatic reports, habitually accompanied by some graphics with most rele- vant data and also some monthly trend or studies of Climate Change.

The information about severe weather situations is common on social media (Martija et al., 2014; Gaztelumendi et al., 2016) and particularly on Facebook. Generally, NMSs inform about the weather warnings they activate, including an explanatory text or some infography (for example, a region under storm risk) and providing a link to the website for further and more detailed information (Wendling et al., 2013). They also publish registered data of precipitation, temperature, wind gusts, etc. and give advices to take into account in extreme situations (heat wave, storms, heavy and abundant rainfall, etc.).

Apart from forecasts and warnings, the analyzed services provide different type of information on subjects related to meteorology through texts, reports, videos, photos or scientific articles. Online published information differs from some accounts to others, such as an eclipse seen from a satellite, videos of tornados, courses and conferences, pollen calendars, reports on air quality, explanations about phenology, halos or auroras formations, records of registered waves, experiments, games, etc. Moreover some NMSs, as Aemet, MetOffice and Meteocat, also organize photography competitions.

The analyzed meteorological services publish daily up to 10 posts, even if the maximum average number of posts per day is around 3 (Fig. 5). Some of these weather services (Aemet, MetOffice, Meteocat, DWD and MetEireann) upload new content in their Facebook page at least once per week. Occasionally, for example on holiday, they are inactive for a longer period of time. Notice that most of the MeteoGalicia's information is provided by its Twitter account (Palacio et al., 2014; Gaztelumendi et al., 2014), due to Twitter is the main social network in some NMSs (Gaztelumendi et al., 2015, 2016).

In USA, most of the information given by NWS account is about severe weather warnings and safety tips related to them. They give this kind of tips through videos and hashtags (\#FloodSafety, \#DroughtSafety, \#LightningSafety), including for example tsunami evacuation maps, links to its website to see flooding in real time and tsunami warnings (indicated with the traffic light colour system). They also provide very different curiosities, such as percentage of people killed by lightning, news of activities of the meteorological service, 
Tsunami History in Japan or advices to see the Perseids. Usually, everything is explained graphically and in a very visual way. The NWS also organizes photography competitions for users, although the interaction with them is nearly inexistent. We have to highlight that they share a lot of information from other weather services related to the NWS (Storm Prediction Center or NWS Southern Region) and from their Twitter accounts (Palacio et al., 2014; Gaztelumendi et al., 2014). Daily, they publish up to twelve posts, but usually no more than two (Fig. 5) and also this meteorological service does not take more than a week without publishing.

In Oceania, we have to highlight the Facebook page of the Bureau of Meteorology, in Australia. Apart from the quality of the pictures, they have hundreds of thousands of followers and the interaction with them is also remarkable. This weather service does not usually use this platform to diffuse neither daily forecasts nor warnings, but it publishes detailed information about meteorological phenomena, climatology, long-range forecasts, security and health warnings and especially pictures of high quality. They share the pictures taken by users, besides expressing their gratitude to the authors and explaining observed phenomena or types of clouds. Photography and questions competitions (Quiz) are also organized. In order to give other information, videos are published and presented by climatologists, hydrologists and meteorologists, amongst others, who explain special phenomena, sometimes questioned by followers, and supported by images and graphics. They also provide links to their website, blog or videos of Youtube in order to expand the information. These posts seem to be interesting to a high number of internet users, since in only one week more than 20000 of them discuss about the published information or react to these messages, so PTAT index is very high (Fig. 5). Generally, their frequency of posts is up to 2 per day, however, the activity decreases or is null on holiday periods.

Finally, in Philippines, Pagasa is especially active in forecast, warnings and thunderstorms vigilance. When severe weather occurs, they are very active and can write up to 50 posts in one day. These posts seem to be very interesting for Internet users because almost 16000 comments are received about the kind of information. Nevertheless, out of severe weather situations, the weather service is not active at all and they can be more than one month without writing. Generally, they write texts with isobar maps and some satellite images and offer links to their own forecasts. Usually they publish neither photos nor videos and the interaction with users it seem to be non-existent.

\section{Conclusions}

Despite the fact that Facebook is a rather recent tool, most of the NMSs use it. In addition to allow weather services to provide detailed information, it also encourages users to give a feedback about what they like or what they consider more interesting. Therefore, together with other social networks like Twitter, nowadays Facebook is an essential tool for many weather services.

In this paper, Facebook accounts of NMSs are analyzed. On the one hand, we gather information about all the NMSs which have an active account at some point, such as number of followers (Likes) and start date. On the other hand, some of the most influential NMS are selected and a more specific analysis of their contents are developed, through Likealyzer tool and by directly checking their historical Facebook content.

Content of their Facebook accounts and how NMSs update meteorological information differ from one to another. Some of them provide information on the weather forecast and curiosities related to it. Others use this social network to monitor severe weather situations or, in particular cases, to diffuse information already published in their Twitter account. In general, followers respond or react better to the photos published; although, in some cases such as Aemet, users seem to like links to additional information too.

Twitter is the main social network in some NMSs. Thus, its Twitter account takes over its Facebook page, where they publish almost the same information.

Facebook accounts of NMSs from Philippines and Australia are the ones with more followers (Likes) and, despite of high LikeRank index, they do not catch the number one up, MetOffice which reaches 89 of 100 . Therefore, globally, this Facebook page can be considered as the most complete and efficient one. However, amongst the NMSs selected, the ones with the lowest LikeRank index are the ones with fewer followers. That is, they have a lower performance of their accounts. On the other hand, NMSs with more followers (Likes) are usually the ones with the highest PTAT index. This seems to be logical since the number of followers is higher and, thus, there are more reactions to the published information. In turn, accounts with less followers obtain a lower PTAT index. We should also add that the highest LikeRank index corresponds to the NMSs that interact the most with users through this tool.

If we consider potential followers, related with the inhabitants from each country, pages that have a higher ratio of followers by thousands of people, do not always match with the biggest NMSs, such as the one from USA. And yet, we can consider some regional weather services, as Meteocat.

We have to keep in mind that, in addition to these potential followers, other factors must be considered, such as the language. People from English-speaking countries can understand and be interested in information published by MetOffice, Australia, NWS ... or vice versa. And same thing can happen with people from countries with the same mother tongue (Spanish, French, etc.). Some information published not only refers to weather or climatology from a region, but to issues affecting the world, for example climate change, severe weather like cyclones, particular phenomena of an area of the planet and so on. 


\section{Data availability}

All the information used has been collected in May 2015 from different public available world wide web sources. The first overview of worldwide National Meteorological Services is based on the list provided by the World Weather Information Service in http://worldweather.wmo.int/en/home.html. Accessing to the websites of each weather service, we select the NMSs that have active accounts on Facebook. Regarding to the information provided in Sects. 2 and 3, we collect all the information from the Facebook account, that is, https://www.facebook.com. In particular, the selected NMSs are analyzed accessing directly to the Facebook public accounts of each weather service, such as, http://www.facebook.com/metoffice, http://www.facebook.com/DeutscherWetterdienst, http://www.facebook.com/Met-Eireann-123518233000, http://www.facebook.com/AgenciaEstatalMeteorologia, http://www.facebook.com/meteogalicia.es, http://www. facebook.com/meteocat, http://www.facebook.com/NWS, http://www.facebook.com/bureauofmeteorology, http://www.facebook.com/PAGASA.DOST.GOV.PH. In relation to the statistical index obtained for the different Facebook accounts, such as, PTAT and LikeRank, we use the LikeAlyzer tool, from http://www.Likealyzer.com.

Acknowledgements. The authors would like to thank the Emergencies and Meteorology Directorate - Security Department - Basque Government for public provision of data and operational service financial support. We also would like to thank all our colleagues from Euskalmet for their daily effort in promoting valuable services for the Basque community.

Edited by: T. Cegnar

Reviewed by: P. Giannopoulos and two anonymous referees

\section{References}

Facebook: Web of Facebook Company Information: http:// newsroom.fb.com/company-info/, last access: July 2016.

Gaztelumendi, S., Orbe, I., Lopez, A., Aranda, J. A., and Anitua, P.: Social media and high impact weather communication in Basque Meteorology Agency, 13th EMS, 11th ECAM, 9-13 September 2013, Reading, UK, 2013.

Gaztelumendi, S., Martija, M., Príncipe, O., and Palacio, V.: An overview of the use of Twitter in National Weather Services, 14th EMS Annual Meeting and 10th European Conference on Applied Climatology (ECAC), 6-10 October 2014, Prague, Czech Republic, 2014.

Gaztelumendi, S., Martija, M., Principe, O., and Palacio, V.: An overview of the use of Twitter in National Weather Services, Adv. Sci. Res., 12, 141-145, doi:10.5194/asr-12-141-2015, 2015.

Gaztelumendi, S., Orbe, I., Salazar, O., Lopez, A., Aranda, J. A., and Anitua, P.: Delivery and communication of severe weather events in Basque Country: the Euskalmet case, Adv. Sci. Res., 13, 87-90, doi:10.5194/asr-13-87-2016, 2016.

Gill, J. and Kreft, P.: Guidelines on Strategies for use of Social Media by National Meteorological and Hydrological Services, WMO-No. 1086, WMO, Geneva, Switzerland, 2012.

Karakayali, N. and Kilic, A.: More Network Conscious Than Ever? Challenges, Strategies, and Analytic Labor of Users in the Facebook Environment, J. Comput.-Mediat. Commun., 18, 61-79, 2013.

LikeAlyzer: Analyze and monitor your Facebook Pages, http:// www.Likealyzer.com, last access: July 2016.

Martija, M., Palacio, V., Príncipe, O., and Gaztelumendi, S.: Meteo adversa y su comunicación vía radio y Twitter, XXXIII Jornadas científicas de la AME, Oviedo, Spain, 2014.

Palacio, V., Martija, M., Príncipe, O., and Gaztelumendi, S.: Servicios meteorológicos y Twitter, XXXIII Jornadas de la AME, Oviedo, Spain, 2014.

Wendling, C., Radisch, J., and Jacobzone, S.: The Use of Social Media in Risk and Crisis Communication, OECD Working Papers on Public Governance, No. 25, OECD Publishing, Paris, France, 2013.

WMO: Weather on the internet and other new technologies, WMO/TD No. 1084, WMO, Geneva, Switzerland, 2001.

WMO: Examples of best practice in communicating weather information, WMO/TD No. 1409, WMO, Geneva, Switzerland, 2007. 